Indexed by

\title{
Scopus
}

\section{ON THE METHODICS OF MATHEMATICAL MODELLING OF POLLUTION OF HYDROLITHOSPHERE BY PETROLEUM PRODUCTS (EXEMPLIFIED BY KURSK OIL TERMINAL)}

Crossref

KOBSON

\section{Vladimir Bredikhin}

Southwest State University,

Faculty of Construction and Architecture, Department of Real Estate Management,

ROAD $=$ Mining, Kursk, Russia water movement, prognosis

\section{Vladimir Khaustov}

Belgorod National Research University, Institute of Earth Sciences, Department of Applied Geology and Mining, Belgorod, Russia

\section{Dmitriy Melkumov}

Southwest State University, Faculty of Construction and Architecture, Department of Real Estate Management, Mining, Kursk, Russia

Key words: petroleum products, lithosphere pollution, petroleum lens, mathematical model, ground-

\section{Cite article:}

Vladimir, B., Vladimir, K., \& Dmitriy, M. [2021]. On the methodics of mathematical modelling of pollution of hydrolithosphere by petroleum products (exemplified by kursk oil terminal). Journal of Applied Engineering Science, 19(1), 258 - 261. DOI:10.5937/jaes0-31038

Online aceess of full paper is available at: www.engineeringscience.rs/browse-issues 


\title{
ON THE METHODICS OF MATHEMATICAL MODELLING OF POLLUTION OF HYDROLITHOSPHERE BY PETROLEUM PRODUCTS (EXEMPLIFIED BY KURSK OIL TERMINAL)
}

\author{
Vladimir Bredikhin ${ }^{1 *}$, Vladimir Khaustov ${ }^{2}$, Dmitriy Melkumov ${ }^{1}$ \\ 'Southwest State University, Faculty of Construction and Architecture, Department of Real Estate \\ Management, Mining, Kursk, Russia \\ ${ }^{2}$ Belgorod National Research University, Institute of Earth Sciences, Department of Applied Geology \\ and Mining, Belgorod, Russia
}

A potential threat of pollution of hydrolithosphere with petroleum and its products due to accidental and technological leaks on a certain industrial object has been analyzed. The author's method of mathematical modelling is described that allows to perform an adequate dynamic modelling of a petroleum products lens in an aquifer. Execution of the resulting model allows to forecast behavior of petroleum products in the conditions of a real geological and hydro-geological cross-section.

Key words: petroleum products, lithosphere pollution, petroleum lens, mathematical model, groundwater movement, prognosis

\section{INTRODUCTION}

Experience of the geoecological research in the last decades shows that the pollution of geological environment with petroleum and its products is very common-is comprises one third of all instances of pollution. Almost all existing petroleum industry enterprises (upstream, midstream and downstream sectors) pollute hydrolithosphere. Many source areas of such pollution are classified as ecological disaster zones [1, 2]. For example, due to accidental and technological leaks of petroleum products, Pyatigorsk and Tuapse oil terminals have become massive sources of pollution of vadose zones and groundwater. Annual leakages of petroleum products with volume ranging from 300 to 500 tonnes have formed pollution hotbeds of $1 \mathrm{~km}^{2}$ (Tuapse) and up to $5 \mathrm{~km}^{2}$ (Pyatigorsk), which cover residential areas of the cities. The surface of groundwater near oil terminals is reported to have a layer of flowing petroleum products with capacity up to 2.0 metres, and the load of the petroleum products in vadose zone is $2-5 \%$ of soil mass.

The fact has to be considered as even small leaks of liquid hydrocarbons may cause disproportionately large amounts of groundwater pollution. For example, 1 liter of gasoline can pollute 2 million liters of underground water to inadmissible concentrations.

\section{MATERIALS AND METHODS}

The relapse of polluting subsoil assets in the area of Kursk oil terminal (Fig. 1) is no exception. Here, the pollution of hydrolithosphere is manifested in form of a continuous petroleum lens, lying on the groundwater surface, polluting it with dissolved petroleum products [3].

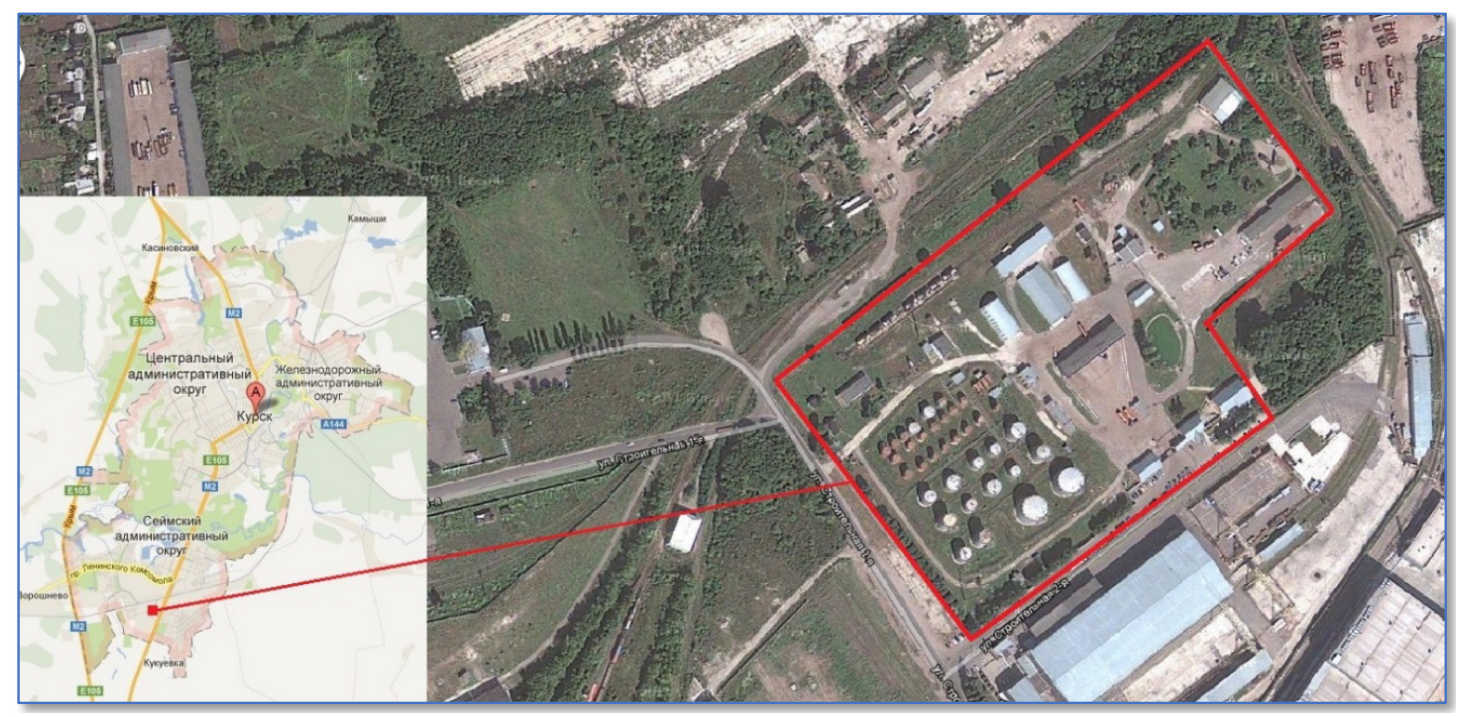

Figure 1: Location of the oil terminal (city Kursk) 


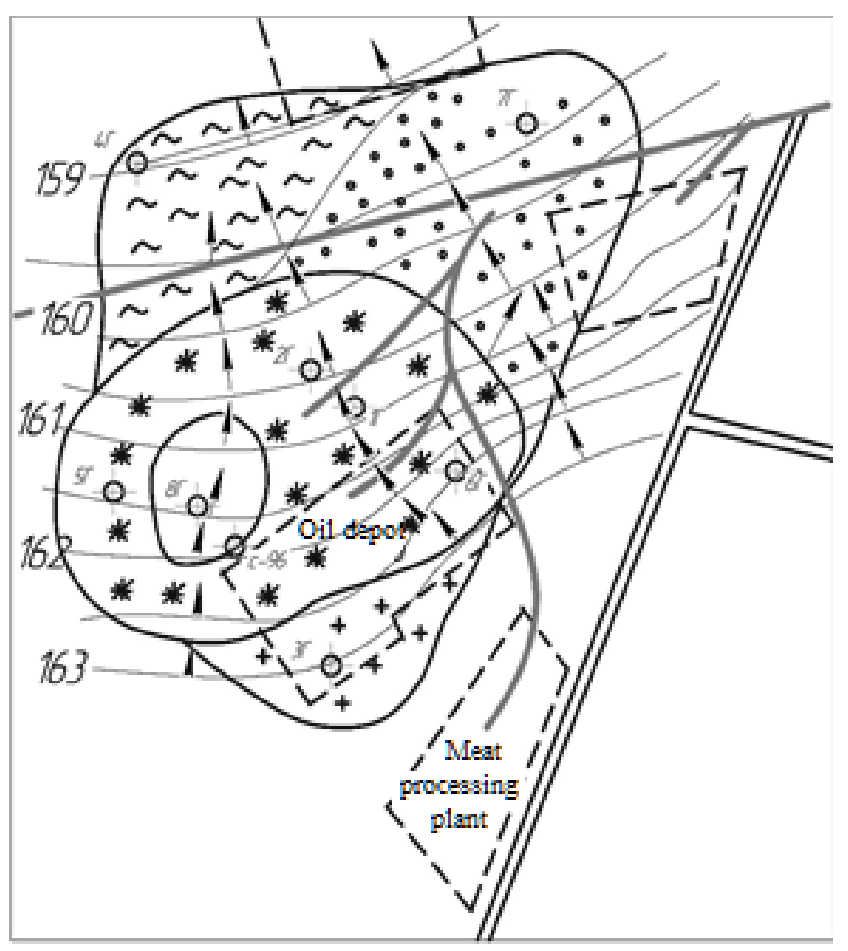

Legend

O- - observation well and its number

V. bydroinogypuyen and the actual derection of movement of grovedwater Exceeding the MPC of oil products in grownchater

from $100020 \mathrm{MPC}$.

$\sim$ from $100000300 \mathrm{MPC}$ \%"7 from 300 and moes

Figure 2: Scheme of groundwater pollution in the area of the oil terminal

The lens of free petroleum products is connected to the territory of the oil terminal at the northern side (Fig. 2).

Maximum capacity of the petroleum column is found in the borehole $8-\mathrm{G}$ and is $1,21 \mathrm{~m}$ in size. The borehole is located at a distance of $5 \mathrm{~m}$ from the buried tank for stor- ing petroleum products. The possibility of leakage of petroleum products from this tank is not excluded, since in neighboring wells the capacity of the petroleum column is reduced to $0.5 \mathrm{~m}$. Slow movement of petroleum lens in the north-north-western direction is clearly evident, and it follows the flow of groundwater towards the stream bed of river Seym. This finding has been recorded in the large-diameter borehole 7-G, which experienced floating petroleum product capacity increase from 0.58 to $0.96 \mathrm{~m}$, from 10.06 .93 to 01.07 .93 respectively.

Moreover, this movement of the "floating" lens has a shape of a "tongue", which is not accidental. It turned out that the front of the lens is moving upon the thalweg of the stream that previously flowed here, as the rocks are heavily washed out in this location.

\section{RESULTS}

In order to get the most accurate prognosis of petroleum product behavior with consideration of modern requirements it is necessary to use methods of mathematical modelling with the aim to build a dynamic mathematical model of petroleum lens in aquifer.

The petroleum lens has formed in the groundwater developed in the alluvial rocks of the Seym River valley (fig. 3).

The rocks are represented by a sandy loam \& loam layer of up to $15 \mathrm{~m}$ (open porosity of loess-like loams-0.23, marl loams-0.28, sandy loams-0.31; the flow rate of groundwater is $0.001-0.005 \mathrm{~m} /$ day). Hydraulic gradient of an aquifer is insignificant and equals 0.001 . The flow rate of $0.001-0.005 \mathrm{~m} /$ day allows groundwater to move for $2 \mathrm{~m}$ per year.

During determining the speed of petroleum movement in rocks, it is necessary to account for the fact that the viscosity of even light oil is significantly higher than the viscosity of water.

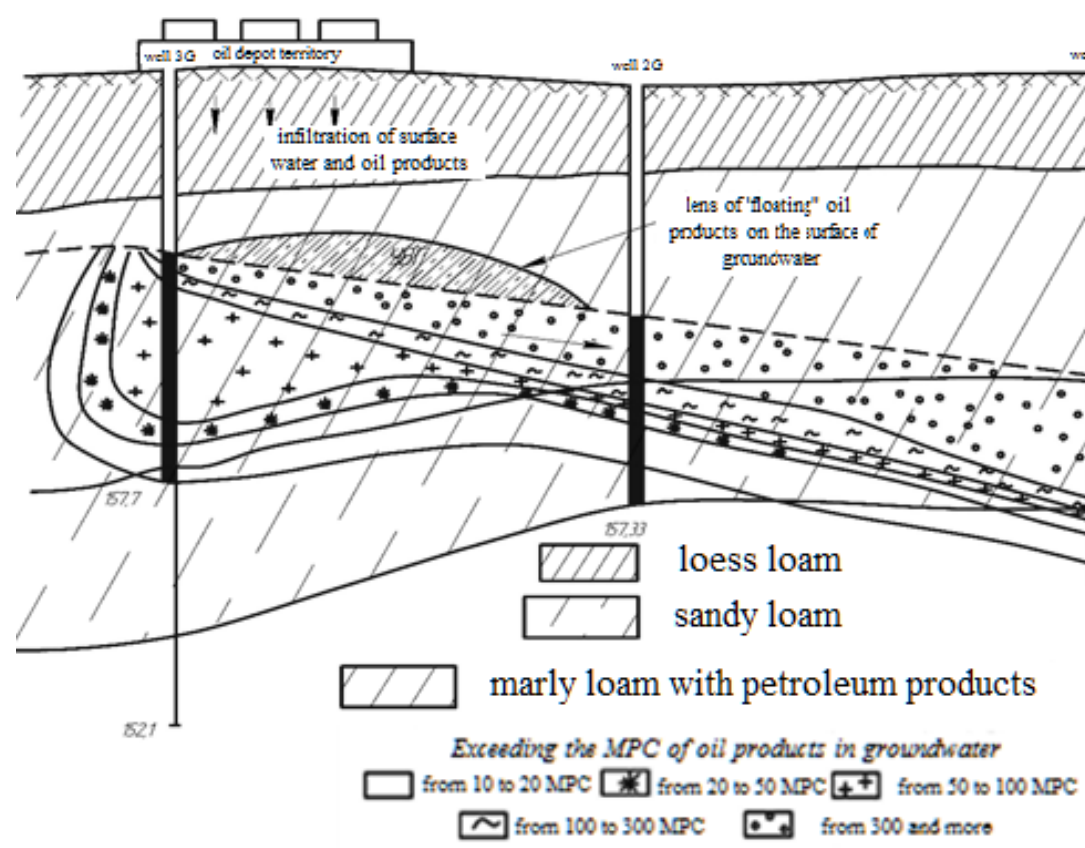

Figure 3: Schematic hydrogeological section in the area of the oil terminal 
To perform predictive mathematical modeling, it is acceptable to assume in the first approximation that the mathematical model that adequately reflects the petroleum lens is described by an exponential second-order Laplace curve of the following form $[4,5]$ :

$Z H(x, y, t)=H(x, y, t)+Z(x, y, t)$

where: $\mathrm{H}(\mathrm{x}, \mathrm{y}, \mathrm{t})$ - the absolute level of the groundwater table at a point with the space coordinates of $x, y$; at time $\mathrm{t}$; which is determined separately for each hydro-contour map drawn from a series of simultaneous measurements of the surface level of the petroleum lens, petroleum films and groundwater surface for all observational hydrogeological wells $(m)$ :

$$
\begin{aligned}
& Z(x, y, t)=A\left(m_{x}(\max ), m_{y}(\max ), t\right) \\
& \times \exp \left(-\left(X_{t}-m_{x}(\max )\right)^{2} / \sigma^{2}\left(x>m_{x}(\max ), x<m_{x}(\max ), t\right)\right. \\
& -\left(Y_{t}-m_{y}(\max )^{2} / \sigma^{2}\left(y>m_{y}(\max ), y<m_{y}(\max ), t\right)\right) / 1000
\end{aligned}
$$

where: $\mathrm{Z}(\mathrm{x}, \mathrm{y}, \mathrm{t})$-capacity of petroleum lens in the point of space with grid coordinates $x, y(m)$;

$A(\operatorname{mx}(\max ), \operatorname{my}(\max ), t)-$ maximum capacity value of the petroleum lens, defined by a series of hydro-contour maps, drawn from a series of simultaneous measurements of all observation wells $(\mathrm{m})$;

$\mathrm{Xt}, \mathrm{Yt}$ - the current space coordinates, which define values of functions $\mathrm{HZ}(),. \mathrm{H}(),. \mathrm{Z}($.$) ;$

$\mathrm{mx}(\max ), \operatorname{my}(\max )$ - spatial coordinates of maximum capacity values of a lens at different times of observation;

$\sigma^{2}\left(y>\operatorname{my}(\max ), y<\operatorname{my}(\max ), \sigma^{2}(x>m x(\max ), x<m x(\max )\right.$ - the variance of the normal distribution, which characterizes the degree of extension of the curve under study.

Since the shape of the exponential curve is affected by the movement of groundwater, the curve is not symmetrical with respect to the maximum value of the lens, so the statistical estimates of the variance differ for areas where the water movement rates and the petroleum lens movement rates coincide, and areas where they have the opposite direction. [6]

As a result, when empirically determining statistical estimates, it is necessary to select experimental data for each such set separately.

The construction of the mathematical model of the petroleum lens is performed in the following sequence:

1. A series of hydro-contour maps is constructed for all observation wells for each observation moment.

2. For each hydro-contour map and for each moment of the entire observation period, the maximum value of the petroleum lens capacity and the coordinates of these points are determined.

3. From the point of the maximum capacity value of the petroleum lens, we draw a vector of the movement direction of groundwater.

4. Using the coordinate axes, we select points with small constant incrementations, so that the number of observations is sufficient for subsequent statistical observa- tion by the parameter of regression models [7, 8].

Further constructions and calculations can be done in the following ways:

- from the point of maximum capacity value of the petroleum lens we construct an auxiliary coordinate axis $\mathrm{Y} 1$ in the direction of groundwater flow vector to the center of the oil lens, through this point construct an auxiliary axis $X$ perpendicular to $Y 1$;

- through the point of the center of the petroleum lens, we draw the auxiliary coordinate system parallel to the previous system. When calculating in this coordinate system in the future, it will be necessary to enter the guiding cosines of the acute angles formed between the main and the auxiliary coordinate systems into the formulas [9].

5. For the mathematical model under study, we use graphic materials to determine the maximum amplitudes and their coordinates at successive time points.

The variance of the function remains unknown, and has to be determined by subsequent calculations.

6. Making tables for each set of values of $x t$ and $y t, Z($.$) .$

7. Based on the available data, we calculate the function $\mathrm{Z1}()=.\mathrm{Z}(.) / \mathrm{A}($.$) for each moment of time.$

8. Define a function $Z 2()=.\exp (\ln (Z 1()$.$) .$

9. Define a function equaling Z3(.) - Z2(.).

10. Calculations are done for the values of $X$, while assuming the values of $Y=0$, and later repeat the steps for the second coordinate axis.

11. Compute $Z 4()=.(Z 3()) 1 /$.2 ;

12. Calculations similar to step (11) are performed for the second coordinate axis.

13. Compute a function $Z 5()=.(X t-m x m a x) / Z 4($.$) .$

14. Compute a function for $Y$ axis in the same manner.

15. The obtained empirical data, collected in a series of tables for different sets and for each moment of time, allows to determine the last unknown parameter in the described mathematical model - the variance. For this task we use the following formula:

$\sigma=f\left(Z_{5}(),. A ; t, X_{t}, Y_{t}\right)$

There are two possible ways to determine this parameter:

- $\quad$ statistical evaluation of sigma value is determined by the following regression equation:

$Z r_{6}=f\left(X_{t}, Y_{t}\right)$

- $\quad$ statistical evaluation of sigma value is done by maximum likelihood estimation method, with formula:

$\sigma_{\text {reg }}=\left(\Sigma Z_{5}().\right) / M_{i}$

where $\mathrm{Mi}$ is the number of experimental observation points of points $Z$ (.) for each of the sets on each coordinate axis and for each time point of observations in the observation wells.

16. While performing calculations for any of the aforementioned options it is preferable to calculate the 
other way as well, and then choose the most appropriate option using the minimum error value of the mathematical model [10] to [12].

17. As the estimates of all unknown parameters of the mathematical model are obtained, it is necessary to perform calculations of the mathematical model for all variants in both arithmetic and logarithmic form $[13,14]$.

18. Based on the obtained statistical estimates of the factors, a forecast of the speed and distance of movement of the following objects is made:

- center of anomaly;

- $\quad$ petroleum film on the sides and the front edge of a petroleum lens;

- the reach time of petroleum film and dissolved petroleum products to the drinking water wells in the village of Akkumulator;

- $\quad$ the reach time of petroleum film and dissolved petroleum products to the Seym stream bed.

\section{CONCLUSION}

Thus, the given method of mathematical modeling of groundwater pollution with petroleum products within a specific pollution source allows to predict the development of this dangerous and complex process. Preliminary calculations confirm the possibility of obtaining good fitting parameters of the behavior of petroleum products in the conditions of the aquifer. A detailed description of a similar prediction of groundwater pollution with petroleum products in the area of the Kursk oil terminal will be presented in a separate article.

\section{REFERENCES}

1. Khaustov, V.V. (2011). Influence of some technogenic processes in the hydrolithosphere on the operational reliability of real estate objects in the Kursk region of the KMA. Proceedings of the Southwest State University, No. 5 (38), 63-72.

2. Khaustov, V.V., Dubyaga, A.P. (2012). On the impact of the development of the Tyrnyauz field on the water ecosystem of the Baksan River (biochemical aspect). Proceedings of the Southwest State University, Engineering and technology, No. 2 (2), 228-235.

3. Khaustov, V.V., Kostenko, V.D., Dubyaga A.P. (2012). On the problem of environmental audit of real estate objects. Proceedings of the Southwest State University, Engineering and technology, No. 2 (3), 258-262.

4. Kostenko, V.D. (2012). On the use of mathematical models in geological and hydrogeological research. Proceedings of the Southwest State University, Engineering and technology, No. 1, 81-92.

5. Kostenko, V.D., Khaustov, V.V., Dubyaga A.P. (2012). On the implementation of a dynamic mathematical model of an aquifer by means of modern information technologies. Proceedings of the Southwest State University, No. 6, 281-286.
6. Wen, M., Ma, Z., Jiang, P. (2017). Study on redox zones of petroleum hydrocarbon contamination in groundwater environment. Advances in Materials, Machinery, Electronics (AMME 2017). 1-7 DOI: 10.1007/978-3-319-55426-6_3

7. Kostenko, V.D. (2012). Assessment of the degree of homogeneity of statistical samples based on modern information technologies. Proceedings of the Southwest State University, Engineering and technology, No. 2, part 2, 247-251.

8. Kostenko, V.D., Khaustov, V.V. (1993). Stochastic mathematical models in the system of hydrogeochemical monitoring. Ecological hydrogeology of the Baltic Sea countries. 124-125.

9. Akulshin, A.A., Bredikhina, N.V., Akulshin An. A., Aksenteva, I.Y., Ermakova N.P. (2019). Development of Filters with Minimal Hydraulic Resistance for Underground Water Intakes. Civil Engineering Journal, 6(5):919-927. DOI: 10.28991/cej-2020-03091517

10. Khaustov, V.V., Bredikhin, V.V., Khaustova, T.V. (2019). Treatment technology of liquid phase at industrial waste landfill. IOP Conf. Ser.: Series: Materials Science and Engineering, 687:066063, DOI: 10.1088/1757-899X/687/6/066063

11. Khaustov, V.V., Ustiugov, D.L. (2017). Formation of drainage waters of Tyrnyauz deposit in ecological aspect. IOP Conf. Series: Earth and Environmental Science. №87, 042006, 1-5, DOI: 10.1088/17551315/87/4/042006

12. Khaustov, V.V., Kruglova, L.E., Bredikhina, N.V., Guseinov T.A. (2019). The impact of flooding on the operational reliability of real estate in the Kursk region. Journal of Applied Engineering Science, vol. 17, br. 2, str. 213-216, DOI: 10.5937/jaes17-21688

13. Shcherbakov, V.I., Akulshin, A.A., Pereverzeva, V.S., Shapovalov, I.G. (2018). Selection of parameters of the filter at design of water wells. International Science Conference SPbWOSCE-2018 "Business Technologies for Sustainable Urban Development. DOI: 10.21869/2223-1560-2018-22-3-6-12

14. Zemo, D. A., O'Reilly, K. T., Mohier, R. E., Magaw, R. I., Devine, C. E., Ahn, S., Tiwary A. K. (2017). Life cycle of petroleum biodegradation metabolite plumes, and implications for risk management at fuel release sites. Integrated Environmental Assessment \& Management. Vol. 13, № 4,714-727. doi.org/10.1002/ ieam. 1848

Paper submitted: 24.02.2020.

Paper accepted: 11.03.2021.

This is an open access article distributed under the CC BY 4.0 terms and conditions. 